\title{
Allylic Nitro Compounds as Nitrite Donors
}

\author{
Harinath Chakrapani, Michael J. Gorczynski, and S. Bruce King \\ Department of Chemistry, Wake Forest University, Winston-Salem, NC 27109
}

S. Bruce King: kingsb@wfu.edu

\section{Abstract}

Allylic nitro compounds were synthesized and evaluated as organic sources of nitrite and nitric oxide. Unactivated allylic nitro compounds do not spontaneously release nitrite and nucleophile promoted nitrite release is slow. However, 2-(nitromethyl)-cyclohex-1-ene-3-one spontaneously dissociates in buffer $(\mathrm{pH}=7.4)$ to release nitrite with a $\mathrm{k}_{\mathrm{obs}}=1.6 \times 10^{-5} \mathrm{~s}^{-1}$. In the presence of $\mathrm{L}$ cysteine, this compound rapidly yields nitrite and reacts with hemoglobin similarly to sodium nitrite. Structural modifications and the nature and amount of nucleophile modulate the rate of nitrite release. In the presence of L-cysteine and ascorbic acid, this compound forms nitric oxide. Together, these results reveal a new structural architecture for the tunable liberation of nitrite and nitric oxide from organic compounds.

\section{Introduction}

Nitrite has long been considered a physiologically inert byproduct of nitric oxide (NO) oxidation. However, recent studies suggest that nitrite plays a crucial role in NO-mediated hypoxic vasodilation, cytoprotection from cardiac and liver ischemia-reperfusion injury, and gene expression. ${ }^{1-5}$ The requirement of oxygen for normal functioning of nitric oxide synthase renders this enzyme ineffective at low oxygen tension and nitrite may assume a role as an important hypoxic source of NO. Deoxyhemoglobin (deoxyHb) reacts with nitrite to generate iron nitrosyl hemoglobin ( $\mathrm{HbFe}(\mathrm{II})-\mathrm{NO})$ and methemoglobin (metHb, $\mathrm{HbFe}(\mathrm{III})$ ), essentially functioning as a competent reductant of nitrite to nitric oxide. ${ }^{6-10}$ Hemoglobin $(\mathrm{Hb})$ may also react with low concentrations of nitrite to generate $S$ nitrosothiols, another possible mechanism for the maintenance of normal vascular tone. ${ }^{11,12}$ Additionally, numerous hypoxic reduction pathways exist for the conversion of nitrite to NO mediated by several heme- and thiol- containing enzymes. ${ }^{13-16}$ For example, respiring mitochondria use ubiquinol to reduce nitrite, while xanthine oxidoreductases, which are structurally similar to bacterial nitrate and nitrite reductases, catalyze nitrite reduction to nitric oxide in the presence of NADH. ${ }^{17}$ Mild biochemical reductants such as ascorbate, 1,2- and 1,4-dihydroxyphenols, and a-tocopherol mediate nitric oxide formation from nitrite. ${ }^{18}$ Physiological sources of nitrite include the normal diet, which contains sizeable quantities $(0.7-181 \mathrm{mg} /$ day $)$ and spontaneous auto-oxidation of endogenously produced nitric oxide (minor). ${ }^{19}$ Furthermore, the intriguing biochemistry of nitrate has emerged, where the body actively concentrates this simple anion for its conversion to nitrite (via commensal bacteria in the mouth) and ultimately NO in the stomach. ${ }^{20}$ Hence, nitrite represents a major intravascular storage pool of $\mathrm{NO}$ and plays a pivotal role in nitric oxide biology.

Correspondence to: S. Bruce King, kingsb@wfu . edu.

Supporting Information Available. Kinetic analysis of nitrite release from 1-6, UV-vis spectrum of the reaction of 7 with deoxyHb and $\mathrm{Hb}$ in the presence of L-cysteine, NMR spectra of the reaction of $\mathbf{7}$ with sodium azide and L-cysteine, and the complete list of authors for ref 1 and 7. This material is available free of charge via the Internet at http://pubs.acs.org. 
Nitrite has been proposed as a potential therapeutic in the treatment of various diseases, including neonatal pulmonary hypertension, subarachnoid hemorrhage associated with vasospasm, and sickle cell disease underscoring the importance of exogenous sources of nitrite. ${ }^{21,22}$ The use of inorganic nitrites precludes both controlled delivery and regulation of nitrite bioavailability and these drawbacks may limit its utility as a therapy. We propose the use of allylic nitro compounds as organic sources of nitrite as an initial strategy to solve the aforementioned problems. The development of organic donors will support our understanding of the underlying mechanisms of nitrite/nitric oxide biology. Furthermore, such compounds may form the basis of novel therapeutic agents and could provide access to versatile NO-based therapeutics including direct reduction to NO (path a, Scheme 1), conversion to $S$-nitrosothiols (path b, Scheme 1), and formation of iron nitrosylated heme proteins (path c, Scheme 1).

Organic nitro compounds present an attractive approach to access a range of nitrite release profiles through simple nucleophilic displacement of the nitro group. In the presence of soft nucleophiles, allylic nitro compounds undergo nucleophilic substitution of the nitro group, presumably accompanied by nitrite release (Scheme 2 ). ${ }^{23,24}$

Allylic nitro compounds undergo regioselective nucleophilic substitution to directly form nitrite but not nitric oxide. ${ }^{23-25}$ The reactivity pattern of nitrite release may be modified by altering the nature and amount of nucleophile or the substitution around the carbon bearing the nitro group. We wish to describe results at developing allylic nitro compounds as sources of nitrite and nitric oxide through such substitution and reduction pathways, preliminary mechanistic studies, and the examination of the reactions of these compounds with hemoglobin.

\section{Results and Discussion}

Allylic nitro compounds 1, 2, and $\mathbf{3}$ were prepared from the corresponding ketones and nitromethane as previously described. ${ }^{24}$ Considering direct nucleophilic substitution $\left(\mathrm{S}_{\mathrm{N}} 2\right)$ as a potential operating mechanism of nitrite release, the rate and amount of nitrite formed over time should decrease as the size of the a-substituent increases. In order to test this idea, compounds $\mathbf{4}$ and $\mathbf{5}$ with a methyl and ethyl group as geminal substituents on the $C$ nitro group were synthesized. ${ }^{24}$ Compound $\mathbf{6}$ was also prepared as a prototype to examine effects of electronic perturbation on nitrite release (Chart 1). ${ }^{24}$

Due to the poor aqueous solubility of compounds $\mathbf{1}-\mathbf{6}$, preliminary investigations were conducted in DMSO. Incubation of allylic nitro compounds (1-6,0.1 M in DMSO) at 37 ${ }^{\circ} \mathrm{C}$ for several days failed to result in nitric oxide or nitrite formation as judged by chemiluminescence spectroscopy suggesting that DMSO does not promote nitrite release. Addition of nucleophiles (1 equivalent) to solutions of $\mathbf{1}-\mathbf{6}$ in DMSO yielded nitrite. Specifically, nucleophile-assisted nitrite release from 1 followed the order thiolate > thioacetate $\gg$ azide > iodide > no nucleophile (Figure 1a). Using phenyl thiolate as a model nucleophile, nitrite release from various allylic nitro compounds was examined (Figure 1b). Increasing steric bulk on the $C$-nitro carbon retarded nitrite release as evidenced by the diminished yields of nitrite from $\mathbf{4}$ and $\mathbf{5}$ compared to $\mathbf{1}$. Ring size did not affect nitrite release as revealed by comparable nitrite yields from $\mathbf{1}, \mathbf{2}$, and $\mathbf{3}$. A vicinal aromatic ring promoted nitrite release as indicated by greater amounts of nitrite released by $\mathbf{6}$ when treated with thiolate than the rest of the substrates tested. These trends in reactivity remain consistent over several days suggesting substitution of the nitro group as the major operative pathway for nitrite release (Figure 1b). Preliminary kinetic studies support a second-order nitrite release process (Supporting Information). 
The poor aqueous solubility and slow nitrite release profiles of the allylic nitro compounds $\mathbf{1}$ - 6 limit their utility as nitrite donors (the most efficient source of nitrite was $\mathbf{6}$, which in the presence of phenyl thiolate yielded $40 \%$ of nitrite over 4 days). However, these studies show that allylic nitro compounds can release nitrite and provide insight on potential structural modifications that could accelerate nitrite release. A suitably placed electronwithdrawing group may enhance the ability to release nitrite by making the carbon bearing the nitro group more susceptible to nucleophilic attack. a-Nitroalkyl enones undergo regioselective substitution by soft nucleophiles under mild conditions. ${ }^{25}$ For example, 2(nitromethyl)-cyclohex-1-ene-3-one (7) reacts with sodium phenyl thiolate in DMF to give 2-(phenylthiomethyl)- cyclohex-1-ene-3-one in $70 \%$ yield (Scheme 3 ). ${ }^{25}$ The allylic nitro compound 7 and 2-(nitromethyl)-cyclohept-1-ene-3-one (8) were synthesized by literature methods from $\mathbf{1}$ and $\mathbf{3}$, respectively (Scheme 3). ${ }^{25}$ The structural resemblance of these nitrite donor candidates to the NO donor FK 409, an allylic nitro compound that spontaneously dissociates to form both nitric oxide and nitrite in buffer, is noteworthy (Chart 2). ${ }^{26-30}$

Allylic nitro compound 7 dissolves in nitrite-free milliQ water and DMSO ( $\$ 6 \%$ ). Negligible amounts of nitrite were detected from this solution after several hours at $25{ }^{\circ} \mathrm{C}$. However, spontaneous nitrite release from $\mathbf{7}$ occurred in a buffered solution. Incubation of $\mathbf{7}$ in $0.1 \mathrm{M}, \mathrm{pH} 7.4$ phosphate buffer (PB) produced $16 \%$ of nitrite after 4 and $51 \%$ after $30 \mathrm{~h}$ at $25{ }^{\circ} \mathrm{C}$ (Figure 2a). Under the same conditions, 8 gave lower yields of nitrite, possibly due to the greater conformational flexibility (and poor $\pi$-orbital overlap) of the seven-membered ring leading to reduced activation of the carbon bearing the nitro group towards nucleophilic substitution by the conjugated ketone. Under pseudo-first-order conditions, the time course of nitrite release from 7 in $\mathrm{PB}(0.1 \mathrm{M}, \mathrm{pH}$ 7.4) showed a predictable pattern of nitrite release with an observed rate of nitrite release of $1.6 \times 10^{-5} \mathrm{~s}^{-1}$ (Figure $2 \mathrm{~b}$ ). Nitrite yields from 7 in Tris buffer were similar to those in PB of comparable molarity and $\mathrm{pH}$ (data not shown). These results confirm the ability of allylic nitro compounds to release nitrite in a buffered solution.

Nitrite release is sensitive to $\mathrm{pH}$ and hydroxide ion concentration. Incubation of $\mathbf{7}$ in $\mathrm{PB}(0.1$ $\mathrm{M}$ ) of varying $\mathrm{pH}$ showed increased yields of nitrite as a function of $\mathrm{pH}$ as judged by chemiluminescence detection. Increased basicity led to greater yields of nitrite until neutral $\mathrm{pH}$, after which point the yield of nitrite remained nearly constant (Figure 2c). In milliQ water, only $3 \%$ of nitrite was observed after $30 \mathrm{~h}$ showing that nitrite release depends on both $\mathrm{pH}$ and ionic strength. The addition of 7 to milliQ water did not alter the $\mathrm{pH}$ of the solution. Varying the buffer molarity at constant $\mathrm{pH}$ provided further evidence for the importance of ionic strength (and hydroxide ion in the buffer-mediated decomposition) for nitrite release from 7 (Figure 2d). Both chemiluminescence and electron paramagnetic resonance analysis (data not shown) failed to provide evidence of nitric oxide formation from $\mathbf{7}$ under these conditions demonstrating that $\mathbf{7}$ is a selective source of nitrite.

Nitrite release from allylic nitro compounds also depended on the presence and the amount of added nucleophile. Treatment of $\mathbf{7}$ with one equivalent of phenyl thiolate or thioacetate in milliQ water afforded nearly quantitative yields of nitrite in 30 minutes, but under the same conditions, the weaker nucleophiles phenyl sulfinate and azide gave diminished nitrite yields (Fig 3a). The biologically relevant nucleophile, L-cysteine, facilitated nitrite release from 7 as a function of $\mathrm{pH}$ and generated nitrite under neutral and basic buffered solutions. Addition of L-cysteine (1 eq.) to 7 at $\mathrm{pH} 7.0$ and 8.7 resulted in quantitative yields of nitrite in 5 minutes (Figure $3 \mathrm{~b}$ ). Similar experiments at $\mathrm{pH} 4.6$ gave only $1 \%$ nitrite after 5 minutes indicating a role for the thiolate ion (Figure 3b). During the same time period, treatment of 7 with other amino acids in $\mathrm{pH} 7.4 \mathrm{~PB}$ gave considerably lower yields of nitrite $(<10 \%)$ revealing the importance of the thiol group as a nucleophile in nitrite formation. However, over 1 hour, incubation of $\mathbf{7}$ with these amino acids produced significant amounts of nitrite 
compared to buffer suggesting potential roles of the carboxylate or amino groups in nitrite formation (Figure 3c).

Independent treatment of 7 with 1 eq. of $\mathrm{N}$-acetyl cysteine, L-methionine, and $\mathrm{N}$-acetyl Lmethionine further reveals the requirement of a thiol/thiolate nucleophile for nitrite release. Addition of $\mathrm{N}$-acetyl cysteine and L-cysteine to $\mathbf{7}$ gives comparable and nearly quantitative nitrite in $5 \mathrm{~min}$ and suggests the dominance of the thiol group over the amino group (Figure 3d). Treatment of $\mathbf{7}$ with L-methionine gives diminished amounts of nitrite indicating that the thiol group is essential for efficient nitrite release (Figure 3d). Finally, the lack of participation of the carboxylate group in nucleophilic displacement was inferred by the observation of negligible amounts of nitrite from the reaction of $\mathbf{7}$ with $\mathrm{N}$-acetyl methionine (Figure 3d). These results clearly indicate that nitrite release from these compounds can be controlled by the relative amount and type of nucleophile present and provide a useful tool for controlled nitrite release.

The release of nitrite from 7 occurs through substitution of the nitro group by a suitable nucleophile (Scheme 4). The products of regioselective nitrite displacement of $\mathbf{7}$ by various nucleophiles have been isolated and characterized previously. ${ }^{25}$ In our hands, the exclusive formation of 2-(azidomethyl)-cyclohex-1-ene-3-one, the product of nucleophilic displacement of nitrite from 7 by sodium azide was observed (Supporting Information). Similarly, NMR studies of the incubation of 7 with L-cysteine in pD 7.4 PB also support this claim (Supporting Information). ${ }^{31}$ The thiol group of L-cysteine is the dominant nucleophilic species but a role for the amino group cannot be completely excluded. The absence of nitrite formation from $\mathbf{7}$ and L-cysteine in milliQ water or at $\mathrm{pH} 4.6$ indicates the requirement of a suitable nucleophile for nitrite formation. Previous work demonstrated that radical transfer processes $\left(\mathrm{S}_{\mathrm{RN}} 1\right)$ in nucleophilic substitution of allylic nitro compounds were not important. ${ }^{25}$ While the observation of the dependence of nitrite release rate on the size of the geminal substituent of the $C$-nitro group in allylic nitro compounds favors direct nitrite displacement $\left(\mathrm{S}_{\mathrm{N}} 2\right)$, pathways that consist of two sequential allylic substitutions $\left(\mathrm{S}_{\mathrm{N}} 2^{\prime}\right)$ cannot be excluded.

Nitrite generated from the allylic nitro compound 7 reacted with heme proteins, thiols, and reductants in a similar fashion as sodium nitrite, giving further evidence of 7's ability to act as a nitrite donor. For example, under the careful exclusion of oxygen, the reaction of nitrite with deoxyhemoglobin produces $\mathrm{HbFe}(\mathrm{II})-\mathrm{NO}$ and methemoglobin in an approximately 1:1 ratio. ${ }^{32}$ A similar spectral pattern was observed when $7(100 \mathrm{mM})$ reacted with deoxyHb $\approx \approx$ $3.3 \mathrm{mM}$ ) in buffer over $8 \mathrm{~h}$ (Figure $4 \mathrm{a}$ ). The fact that only $16 \%$ of nitrite was formed from the spontaneous dissociation of $\mathbf{7}$ in buffer after $16 \mathrm{~h}$ reconciled the observed incomplete reaction of deoxyhemoglobin under these conditions. OxyHb also reacted with sodium nitrite to form methemoglobin with characteristic spectral features. ${ }^{9}$ Reaction of oxyHb $(3.47 \mathrm{mM})$ with $7(100 \mathrm{mM})$ in $\mathrm{pH} 7.4 \mathrm{~PB}(0.1 \mathrm{M})$ produced these characteristic gradual decreases in absorbances at $540 \mathrm{~nm}$ and $576 \mathrm{~nm}$ with concomitant increases in absorbances at $630 \mathrm{~nm}$ and $496 \mathrm{~nm}$ over $4 \mathrm{~h}$ (Figure $4 \mathrm{~b}$ ). This spectral behavior mimicked the sodium nitrite-mediated transformation of $\mathrm{Hb}$ to metHb as reported by Doyle and coworkers. ${ }^{9}$ Again, the addition of L-cysteine to the reaction of $\mathbf{7}$ with deoxyHb and oxyHb greatly enhanced the rate of reaction further illustrating the ability of thiols to induce nitrite release from these allylic nitro compounds. (Supporting Information). ${ }^{33-35}$

Under acidic conditions, nitrite reacts with thiols to form $S$-nitrosothiols, which have been postulated as important physiological storage forms of nitric oxide. ${ }^{36}$ Reaction of $\mathbf{7}$ with Lcysteine (1 eq.) in $\mathrm{pH} 7.4 \mathrm{~PB}$ followed by treatment with acidified-cysteine formed a red solution with a characteristic spectral pattern for $S$-nitrosocysteine $\left(\lambda_{\max }=542 \mathrm{~nm}\right){ }^{37}$ Chemiluminescence assay also independently confirmed the formation of $S$-nitrosothiol. 
Again, these results support thiol-mediated nitrite release from $\mathbf{7}$ and reveal the ability of allylic nitro compounds to $S$-nitrosate a thiol in a manner similar to inorganic nitrite.

Finally and perhaps most importantly in terms of biology, these allylic nitro compounds act as nitric oxide prodrugs under mild reducing conditions, as would be expected of a nitrite donor. Ascorbic acid comprises an important component of gastric juice and is a vital component in the physiological nitric oxide generation from nitrite. Several reports employ nitrite and ascorbic acid mixtures as masked NO sources for therapeutic purposes. ${ }^{38-39}$ For example, mixtures of sodium nitrite and ascorbic acid blocked the growth of Streptococus mutans. ${ }^{40}$ The reaction of ascorbic acid with $7 \mathrm{in} \mathrm{pH} 7.0 \mathrm{~PB}$ yielded nitric oxide, as detected by chemiluminescence headspace analysis $(\approx 0.1 \%)$. At $\mathrm{pH} 7.0$, in the presence of Lcysteine, even higher amounts of $\mathrm{NO}(\approx 3 \%)$ formed in the reaction headspace after $10 \mathrm{~min}$ corroborating nitrite formation and confirming that $\mathbf{7}$ is a source of nitric oxide. Together, these results demonstrate that allylic nitro compounds, such as 7, can specifically act as a selective source of nitrite (in the presence of thiol) or nitric oxide (in the presence of thiol and ascorbic acid). This compartmentalized reactivity makes these compounds mechanistically-unique nitrite donors.

\section{Summary}

Allylic nitro compounds dissociate in buffer to release nitrite with vastly different rate profiles that depend on the nature and relative amount of nucleophile and by the steric and electronic perturbations of the carbon framework. The addition of an electron-withdrawing group enhances nitrite release, particularly in the presence of sulfur nucleophiles. Allylic nitro compound 7 behaved as a stable precursor to both nitrite and nitric oxide. This compound released nitrite in buffer and the addition of L-cysteine increases the rate of nitrite release. Compound $\mathbf{7}$ also reacted with hemoglobin in a similar fashion to sodium nitrite and $S$-nitrosated thiols under acidic conditions. Reaction of $\mathbf{7}$ with ascorbic acid in the presence of L-cysteine generates nitric oxide showing that this three-component mixture represents a unique system for nitric oxide formation. These findings reveal allylic nitro compounds as a new group of nitrite/nitric oxide sources that have tunable release profiles making them potentially useful in the development of therapeutic agents.

\section{Experimental Section}

NMR spectra were recorded on a $300 \mathrm{MHz}$ Bruker NMR spectrometer. Nitromethane, nitroethane, 1-nitropropane, cyclopentanone, cyclohexanone, cycloheptanone, 1phenylpropanone, sodium nitrite, sodium phenyl thiolate, L-cysteine. $\mathrm{HCl}, \mathrm{L}$-methione, Lproline, L-alanine, L-serine, N-acetyl-L-cysteine, N-acetyl-L-methionine, sodium phenyl sulfinate, potassium thioacetate, sodium azide, sodium hydrogen phosphate, sodium dihydrogen phosphate, 3-chloroperoxybenzoic acid, 2,2' -dimethyl ethylenediamine, triethylamine, pyridinium chlorochromate, ascorbic acid were purchased from SigmaAldrich and used as received. Hexanes, ethyl acetate, methylene chloride, acetonitrile, dimethyl sulfoxide, ethanol were purchased from Sigma-Aldrich and used as received. Compounds $\mathbf{1}-\mathbf{8}$ were prepared by known methods, and spectrally characterized before use. ${ }^{24-26}$ Plots were generated and analyzed using the curve fitting program of Origin 5.0 and the $R^{2}$ values of linear fits are reported.

\section{Nitrite Analysis}

Test compounds were weighed into vials $(3 \mathrm{~mL})$, sealed with rubber septa and deoxygenated with argon for 20 minutes. Compounds $\mathbf{1}-\mathbf{6}$ were dissolved in DMSO (100 mM) while compounds $\mathbf{7}$ and $\mathbf{8}$ were dissolved in milliQ water or buffer (various $\mathrm{pH}$ or molarity) containing $\approx 5 \%$ DMSO to give final concentrations of $5-10 \mathrm{mM}$. The samples were 
incubated at $37^{\circ} \mathrm{C}(\mathbf{1}-\mathbf{6})$ or $25^{\circ} \mathrm{C}(\mathbf{7}$ and $\mathbf{8})$ and aliquots $(50 \mu \mathrm{L})$ of the reaction solutions were periodically injected into the reaction chamber of a Sievers 280 Nitric Oxide Analyzer (NOA). For nitrite analysis, the reaction chamber contained $1 \% \mathrm{w} / \mathrm{v}$ potassium iodide in glacial acetic acid, a solution that reduces nitrite to NO. For experiments involving nucleophile additives, equimolar solutions of the nucleophile (in milliQ water or buffer) and the allylic nitro compound (in DMSO) were mixed and then diluted with the milliQ water or buffer of suitable molarity and $\mathrm{pH}$ to give a final concentration of 5-10 mM. For example, independent solutions of L-cysteine $(23 \mathrm{mg}, 0.13 \mathrm{mmol})$ in $\mathrm{pH} 7.4$ phosphate buffer $(1 \mathrm{~mL})$ and $7(21 \mathrm{mg}, 0.13 \mathrm{mmol})$ in DMSO $(1 \mathrm{~mL})$ were prepared. Aliquots $(50 \mu \mathrm{L})$ of both these solutions were placed in a vial and diluted with $\mathrm{pH} 7.4$ phosphate buffer $(900 \mu \mathrm{L})$ to give a final concentration of $7 \mathrm{mM}$.

\section{Nitric oxide analysis}

Nitric oxide analyses were carried out using the same experimental procedure as nitrite analysis except that aliquots $(250 \mu \mathrm{L})$ of the reaction headspace and solution were injected into the reaction chamber that only contained milliQ water $(2 \mathrm{~mL})$. For these experiments, solutions of the allylic nitro compounds and nucleophile were generally $20 \mathrm{mM}$.

\section{Hemoglobin Preparation}

Normal adult hemoglobin was prepared as described earlier. ${ }^{41}$ The hemoglobin sample was pelleted in liquid nitrogen and stored at $-80^{\circ} \mathrm{C}$. Hemoglobin samples used for experiments were thawed and used within $24 \mathrm{~h}$. Thawed hemoglobin samples were further centrifuged to remove any precipitated or denatured protein. The absence of denatured protein was confirmed by absorption spectroscopy. Deoxyhemoglobin was formed by gently flowing argon over a solution of oxyHb in argon-saturated buffer in a cuvette with a rubber septum until the absorption spectrum showed the complete removal of oxygen.

\section{Absorption Spectroscopy}

Hemoglobin solutions ( $3.47 \mathrm{mM}$ in heme) in $0.1 \mathrm{M} \mathrm{PB}$ (pH 7.4) were treated with 7 or 8 $(100 \mathrm{mM})$ and placed in a cuvette under anaerobic conditions. Readings were taken every 30 $\min$ for $12 \mathrm{~h}$ on a Cary $100 \mathrm{UV}$-vis spectrometer at $25^{\circ} \mathrm{C}$. Similar experiments were performed in the presence of L-cysteine (1 eq.) with spectra being recorded every 1 min for 90 min. Similar experiments were performed with oxyhemoglobin. Mixtures of L-cysteine with oxyHb and deoxyHb over the reported time periods provided controls.

\section{S-Nitrosothiol formation}

A solution of L-cysteine ( $50 \mu \mathrm{L}, 0.13 \mathrm{M}$ in pH 7.0 PB) and 7 (50 $\mu \mathrm{L}, 0.12 \mathrm{M}$ in DMSO) were diluted in a spectrophotometric vial was treated with and $100 \mu \mathrm{L}$ aqueous solution of L-cysteine ( $1 \mathrm{M}$ in milliQ water) acidified with $2-3$ drops of dilute $\mathrm{HCl}$. The resulting solution rapidly turned red and the UV-visible spectrum was recorded. Aliquots $(50 \mu \mathrm{L})$ of this solution were injected into the NOA reaction chamber containing L-cysteine ( $3 \mathrm{M})$ and $\mathrm{CuCl}(100 \mu \mathrm{M})$ in $\mathrm{pH}$ 7.0 PB. This system converts $S$-nitrosothiols to NO.

\section{Ascorbic Acid Experiments}

A solution of ascorbic acid ( $100 \mu \mathrm{L}, 2 \mathrm{M}$ in $\mathrm{pH} 7.4 \mathrm{~PB})$ was added to a solution of $7(50 \mu \mathrm{L}$, $2 \mathrm{M}$ in DMSO) at $25^{\circ} \mathrm{C}$ and diluted with $400 \mu \mathrm{L} \mathrm{pH} \mathrm{7.4} \mathrm{PB}$. After $1 \mathrm{~h}$, an aliquot $(250 \mu \mathrm{L})$ of the headspace was injected into the reaction chamber containing only milliQ water to determine NO release. The experiment with L-cysteine was conducted in a similar fashion, except that a solution of $50 \mu \mathrm{L}$ L-cysteine ( $2 \mathrm{M}$ in $\mathrm{pH} 7.4 \mathrm{~PB}$ ) was added before the ascorbic acid and headspace NO was recorded after $10 \mathrm{~min}$. Controls using sodium nitrite and ascorbic acid give similar results of nitric oxide release by chemiluminesence. 


\section{Supplementary Material}

Refer to Web version on PubMed Central for supplementary material.

\section{Acknowledgments}

This work was supported by the National Institutes of Health (HL 62198, SBK). The NMR spectrometers used in this work were purchased with partial support from NSF (CHE-9708077) and the North Carolina Biotechnology Center (9703-IDG-1007).

\section{References}

1. Gladwin MT, et al. Nat Chem Biol. 2005; 1:308-314. [PubMed: 16408064]

2. Dejam A, Hunter CJ, Schecheter AN, Gladwin MT. Blood Cells Mol Dis. 2004; 32:423-429. [PubMed: 15121102]

3. Bryan NS, Fernandez BO, Bauer SM, Garcia-Saura MF, Milsom AB, Rassaf T, Maloney RE, Bharti A, Rodriguez J, Feelisch M. Nat Chem Biol. 2005; 1:290-297. [PubMed: 16408059]

4. Webb A, Bond R, Mclean P, Uppal R, Benjamin N, Ahluwalia A. Proc Natl Acad Sci USA. 2004; 101:13683-13688. [PubMed: 15347817]

5. Duranski M, Greer J, Dejam A, Jaganmohan S, Hogg N, Langston W, Patel R, Yet S, Wang X, Kevil C, Gladwin M, Lefer D. J Clin Invest. 2005; 115:1232-1240. [PubMed: 15841216]

6. Kim-Shapiro DB, Gladwin MT, Patel RP, Hogg N. J Inorg Biochem. 2005; 99:237-246. [PubMed: 15598504]

7. Cosby K, et al. Nat Med. 2003; 12:1498-1505. [PubMed: 14595407]

8. Brooks J. Proc Royal Soc B. 1937; 123:368-382.

9. Doyle MP, Pickering RA, Deweert TM, Hoekstra JW, Pater D. J Biol Chem. 1981; 256:1239312398. [PubMed: 7298665]

10. Huang Z, Shiva S, Kim-Shapiro D, Patel R, Ringwood L, Irby C, Huang K, Ho C, Hogg N, Schechter A, Gladwin M. J Clin Invest. 2005; 115:2099-2107. [PubMed: 16041407]

11. Nagababu E, Ramasamy S, Rifkind JM. Nitric Oxide Biol Chem. 2006; 15:20-29.

12. Angelo M, Singel DJ, Stamler JS. Proc Natl Acad Sci USA. 2006; 103:8366-8371. [PubMed: 16717191]

13. Lundberg JO, Weitzberg E, Lundberg JM, Alving K. Gut. 1994; 35:1543-1546. [PubMed: 7828969]

14. Benjamin N, O'driscoll F, Dougall H, Duncan C, Smith L, Golden M, Mckenzie H. Nature. 1994; 370:25-26. [PubMed: 8015600]

15. Li H, Samouilov A, Liu X, Zweier JL. J Biol Chem. 2004; 279:16939-16946. [PubMed: 14766900]

16. Kozlov AV, Staniek K, Nohl H. FEBS Lett. 1999; 454:127-130. [PubMed: 10413109]

17. Gangolli SD, Van Der Brandt PA, Feron VJ, Janowsky C, Koeman JH, Speijers GJ, Spiegelhalder B, Walker R, Wisnok JS. Eur J Pharmacol. 1994; 292:1-38. [PubMed: 7867685]

18. Bartsch H, Ohshima H, Pignatelli B. Mutat Res. 1988; 202:307-324. [PubMed: 3057363]

19. Sies H, Sharov VS, Klotz LO, Briviba K. J Biol Chem. 1997; 272:27812-27817. [PubMed: 9346926]

20. Lundberg JO, Weitzberg E, Cole JA, Benjamin N. Nat Rev Microbiol. 2004; 2:593-602. [PubMed: 15197394]

21. Pluta RM, Dejam A, Grimes G, Gladwin MT, Oldfield EH. J Am Med Assoc. 2005; 293:14771484.

22. Hunter CJ, Dejam A, Blood AB, Shields H, Kim-Shapiro DB, Machado RF, Tarekegn S, Mulla N, Hopper AO, Schecheter AN, Power GG, Gladwin MT. Nat Medicine. 2004; 10:1122-1127.

23. Tamura R, Kamimura A, Ono N. Synthesis. 1991:423-434.

24. Ono N, Hamamoto I, Yanai T, Kaji A. J Chem Soc Chem Commun. 1985:523-524.

25. Tamura R, Katayama H, Watabe K, Suzuki H. Tetrahedron. 1990; 46:7557-7568. 
26. Ohtsuka M, Hombo T, Esumi K. Cardiovascular Drug Rev. 1994; 12:2-15.

27. Yoshida K, Yasuhiro K. Curr Med Chem. 2005; 5:675-685.

28. Shinichi F, Yoshimi H, Yasuko K, Mie N, Mitsuko O, Shigetaka N, Kazuhiro M, Masayuki K, Yasuhiro K. J Pharmacol Exp Ther. 1997; 282:236-242. [PubMed: 9223559]

29. Decout JL, Roy B, Fontecave M, Muller JC, Williams PH, Loyaux D. Bioorg Med Chem Lett. 1995; 5:973-978.

30. Fukuyama S, Kita Y, Hirasawa Y, Sato A, Morokoshi N, Koda S, Yasuda T, Oka S, Sakurai H. Free Rad Res. 1995; 23:443-452.

31. (a) Hamilton DS, Zhang X, Dang Z, Hubatsch I, Mannervik B, Houk KN, Ganem B, Creighton DJ. J Am Chem Soc. 2003; 125:15049-15058. [PubMed: 14653739] (b) Joseph E, Eiseman JL, Hamilton DS, Wang H, Tak H, Ding Z, Ganem B, Creighton DJ. J Med Chem. 2003; 46:194-196. [PubMed: 12502374]

32. Huang KT, Keszler A, Patel N, Patel RP, Gladwin MT, Kim-Shapiro DB, Hogg N. J Biol Chem. 2005; 280:31126-31131. [PubMed: 15837788]

33. Suschek CV, Schewe T, Sies H, Kroncke KD. Biol Chem. 2006; 387:499-506. [PubMed: 16740120]

34. Weller R. Exp Derm. 2003; 28:511-514.

35. Ormerod AD, White MI, Shah SAA, Benjamin N. Brit J Dermatol. 1999; 141:1051-1053. [PubMed: 10606851]

36. Williams DLH. Acc Chem Res. 1999; 32:869-876.

37. Wink DA, Kim S, Coffin D, Cook JC, Vodovotz Y, Christodoulou D, Jourd'heuil D, Grisham MB. Methods Enzymol. 1999; 301:201-211. [PubMed: 9919568]

38. Carlsson S, Weitzberg E, Wiklund P, Lundberg JO. Antimicrob Agents Chemother. 2005; 49:2352-2355. [PubMed: 15917532]

39. Carlsson S, Govoni M, Wiklund P, Weitzberg E, Lundberg JO. Antimicrob Agents Chemother. 2003; 47:3713-3718. [PubMed: 14638471]

40. Radcliffe CE, Lamb R, Blinkhorn AS, Drucker DB. J Dent. 2003; 31:367-370. [PubMed: 12799122]

41. Huang J, Kim-Shapiro DB, King SB. J Med Chem. 2004; 47:3495-3501. [PubMed: 15214777]

J Am Chem Soc. Author manuscript; available in PMC 2012 October 26. 

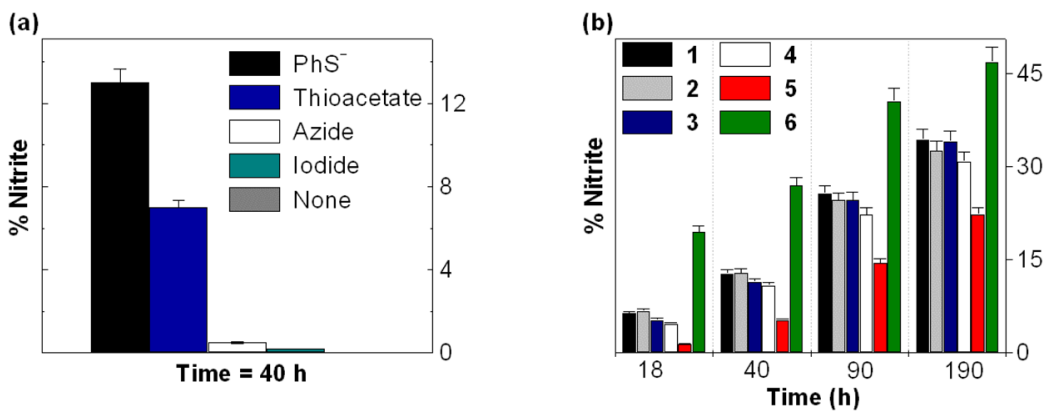

Figure 1.

(a) Nitrite release from $1(0.1 \mathrm{M})$ treated with various nucleophiles $\left(1\right.$ eq.) at $37{ }^{\circ} \mathrm{C}$ in DMSO (b) Time course of nitrite release from $0.1 \mathrm{M}$ solutions of $\mathbf{1}-\mathbf{6}$ treated with 1 eq. $\mathrm{PhSNa}$ in DMSO at $37^{\circ} \mathrm{C}$. 

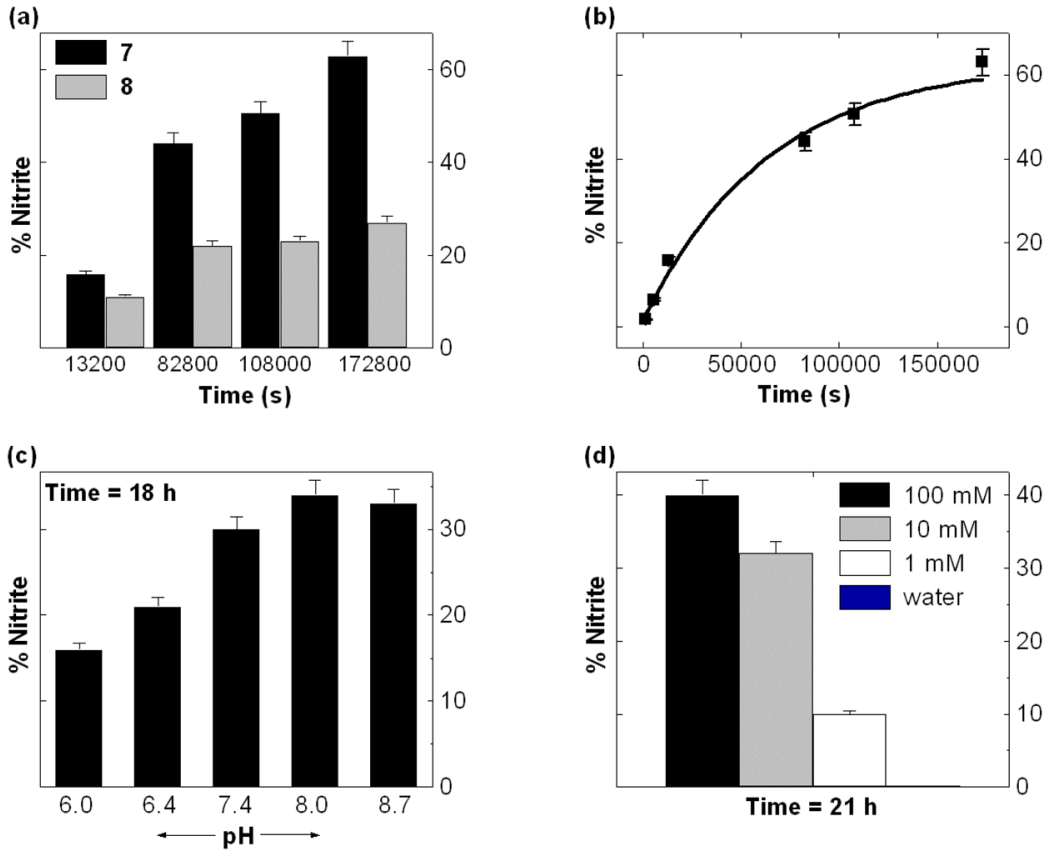

Figure 2.

(a) Comparison of nitrite release from 7 and $\mathbf{8}$ in $0.1 \mathrm{M} \mathrm{pH} 7.4$ buffer (b) Time course of nitrite release from 7 in $0.1 \mathrm{M} \mathrm{pH} 7.4$ phosphate buffer (c) Comparison of nitrite release from 7 in $0.1 \mathrm{M} \mathrm{PB}$ of varying $\mathrm{pH}$ (d) Comparison of nitrite release from 7 in $\mathrm{PB}$ of varying ionic strength at neutral $\mathrm{pH}$. 

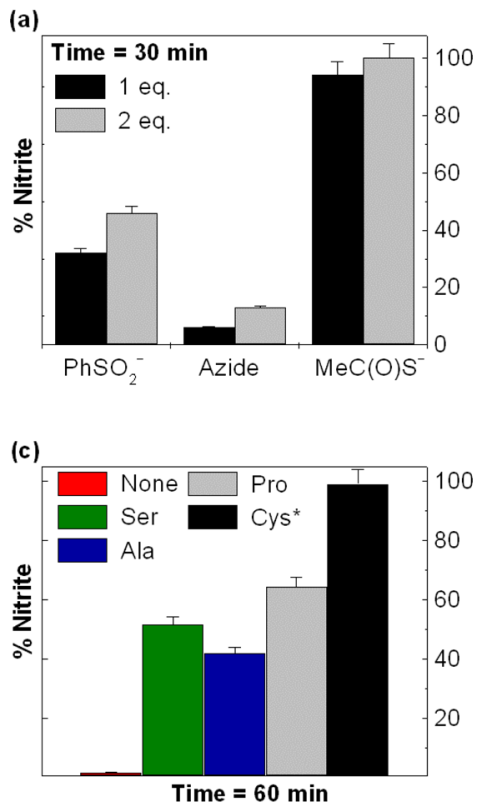
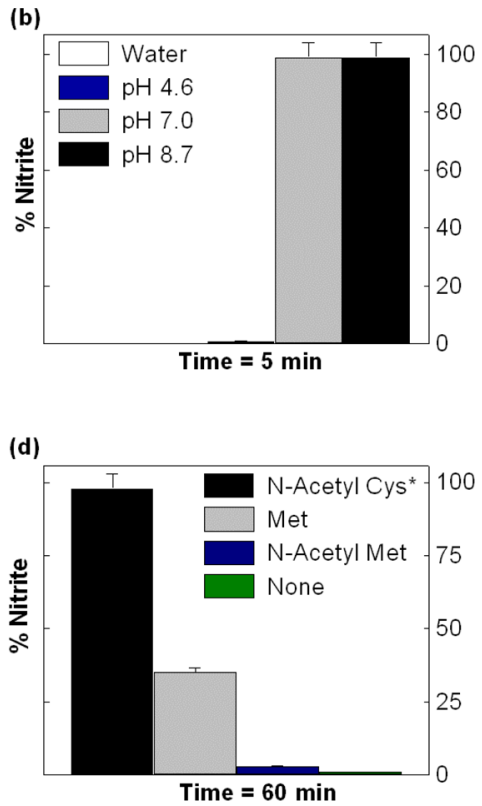

Figure 3.

(a) Nitrite release from 7 in milliQ water upon treatment with various nucleophiles (b) Effect of L-cysteine on nitrite release from 7 in milliQ water and $0.1 \mathrm{M} \mathrm{PB}$ of varying $\mathrm{pH}$ (c) Effect of added amino acid on nitrite release from 7 in $0.1 \mathrm{M} \mathrm{pH} 7.4 \mathrm{~PB}$. (d) Effect of added protected amino acid on nitrite release from 7 in $0.1 \mathrm{M} \mathrm{pH} 7.4 \mathrm{~PB}$. *Nitrite measurements done after 5 min. 

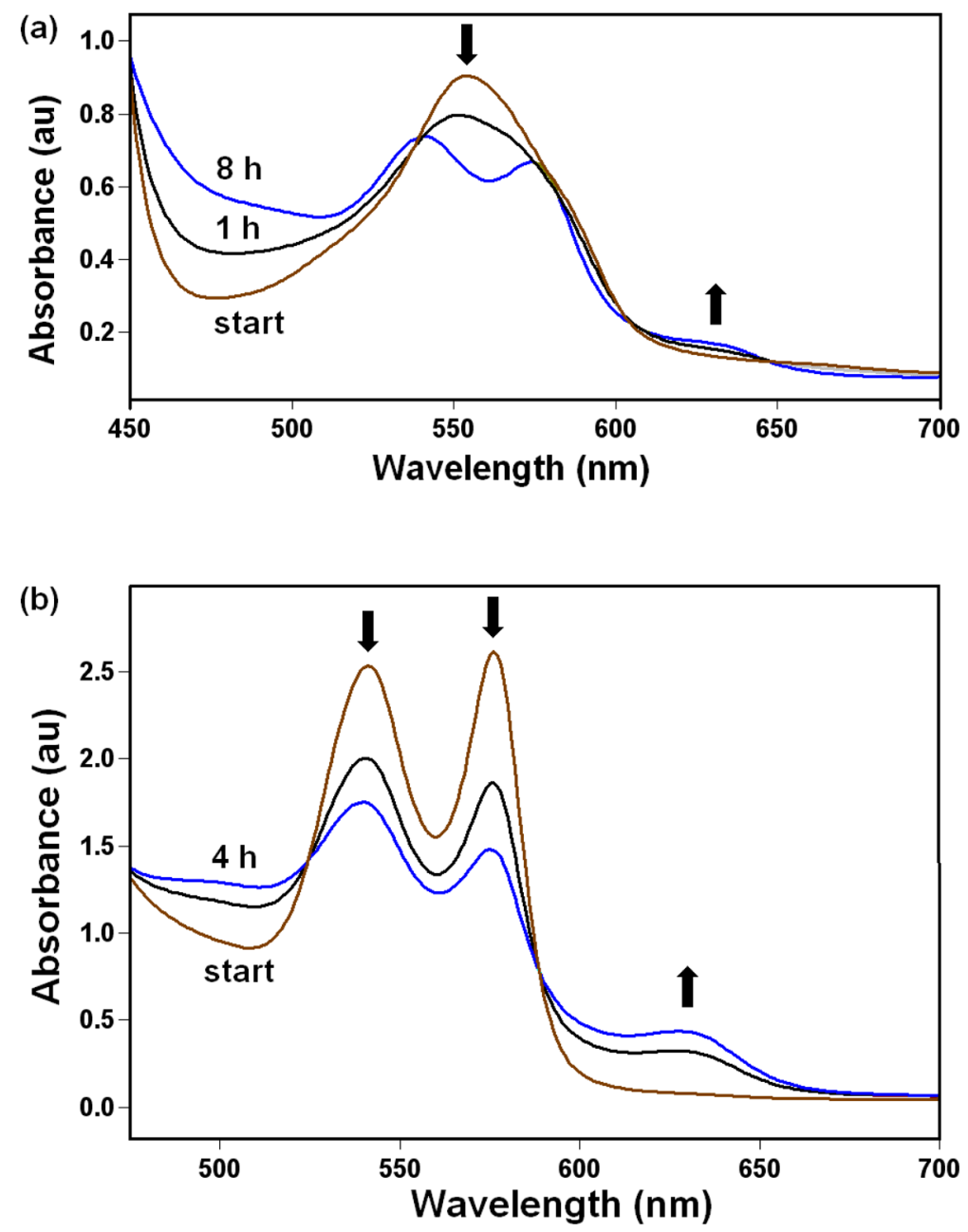

Figure 4.

Spectral features of (a) deoxyHb treated with $7(0.1 \mathrm{M})$ in buffer (b) oxyHb treated with 7 $(0.1 \mathrm{M})$ in buffer. 


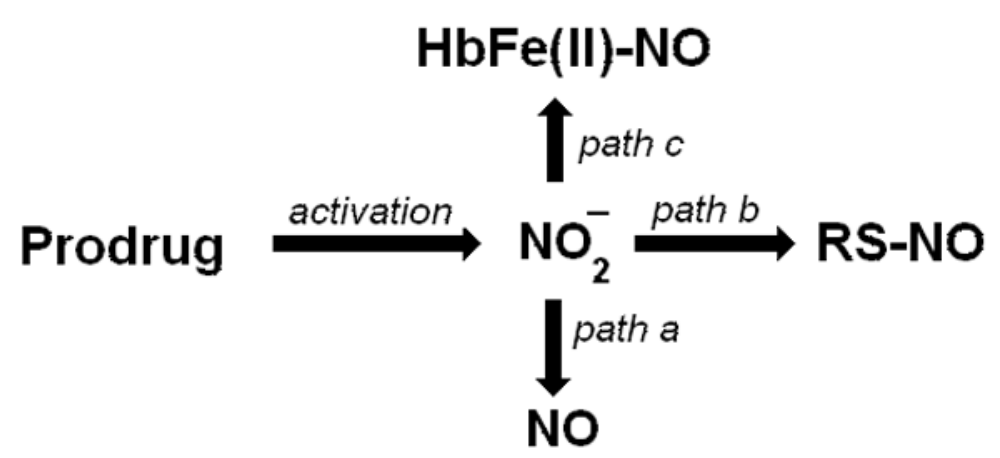

Scheme 1. 


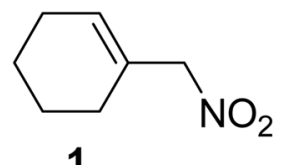

1

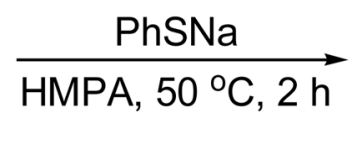

$$
\overrightarrow{\mathrm{HMPA}, 50^{\circ} \mathrm{C}, 2 \mathrm{~h}}
$$

Scheme 2.

Nucleophilic substitution of allylic nitro compounds

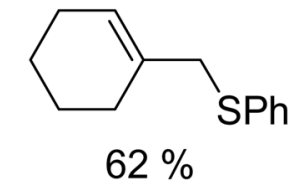


<smiles>O=C1CCCC=C1C[SnH3]</smiles><smiles>[H][Y9]([H])([H])[C@H]1CCCCC1C[N+](=O)[O-]</smiles>

Scheme 3.

Nucleophilic displacement of nitrite from 7 by $\mathrm{PhSNa}$ and synthesis of $\mathbf{7 , 8}$ from 1, 3 . 


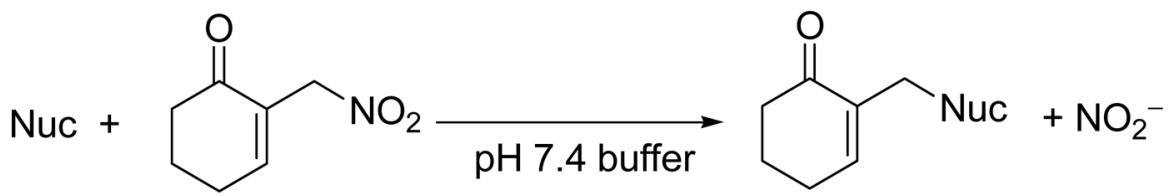

Nuc $=$ Cysteine, $\mathrm{OH}^{-}$, Phosphate

Scheme 4.

Proposed $\mathrm{S}_{\mathrm{N}}$ 2-type mechanism of nitrite release from 7 . 


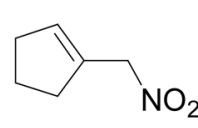

2

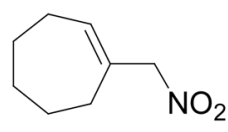

3

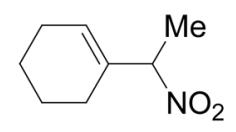

4

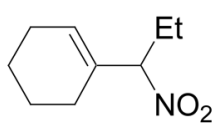

5

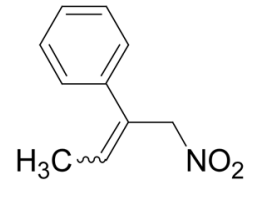

6

Chart 1.

Some allylic nitro compounds as candidate nitrite donors. 


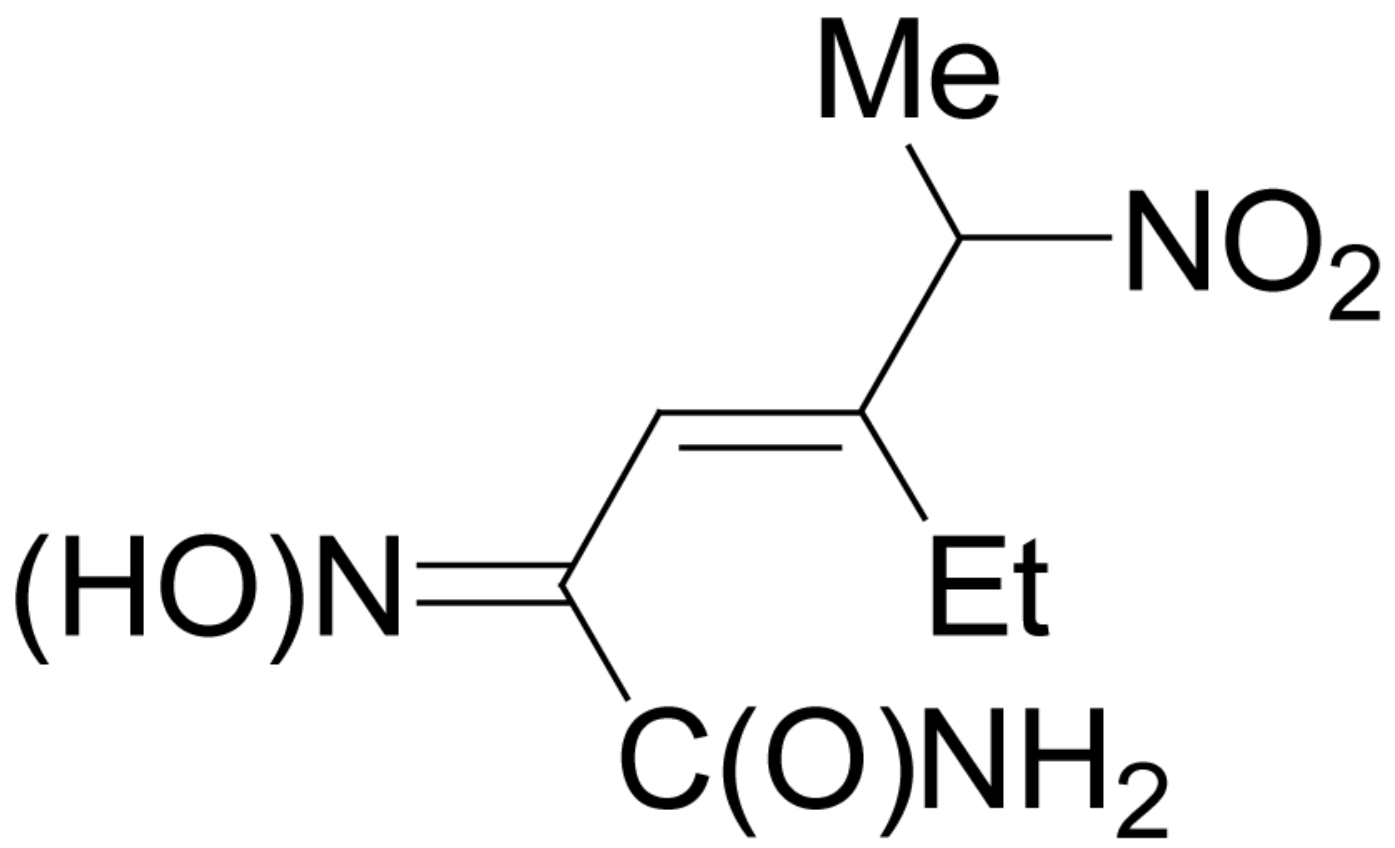

Chart 2.

Structure of FK 409 